\title{
CHANGING STUDENTS' ATTITUDES TOWARDS STATISTICS THROUGH PROJECT-BASED LEARNING IN AEROSPACE ENGINEERING
}

\author{
O. Trull, F. Sempere-Ferre, N. Martínez-Alzamora, V. Sánchez-Anguix \\ Universitat Politècnica de Valencia (SPAIN)
}

\begin{abstract}
The application of project-based learning (PBL) in a course of statistics in the BSc. Degree in Aerospace Engineering at the Higher Technical School of Design Engineering at Universitat Politècnica de València has led to a significant and positive change in students' attitude towards learning and acquisition of statistical concepts. More specifically, PBL has provided the opportunity for students to overcome the limitations and preconceived barriers of classic learning methodologies and lectures, by applying statistical tools to improve the design of a cardboard glider.

The PBL strategy is implemented by means of a long-term project that is carried out in teams ranging from three to four students. The project is closely supervised by the laboratory lecturers, who act as mentors to the students throughout the whole term. At the initial stage, all the teams are given the same initial design of a cardboard glider, and students apply descriptive statistics to characterize and describe the flight of the original design. Then, students are given a flight benchmark that they should improve with their final designs. By applying inference, regression, and design of experiment tools, students modify the original design to beat the benchmark. The results of a survey that has been conducted suggest that, through this methodology, students not only apply and experiment with the concepts that they learn, but their motivation, engagement, and interest in statistics is also increased.
\end{abstract}

Keywords: attitudes, statistics, project-based learning

\section{INTRODUCTION}

Statistics are becoming increasingly important in engineering processes, both in industrial production and in development and research. The use of quality methods, lean manufacturing, and 6-sigma is increasingly common. This situation is causing a modernization in the statistical methods taught in universities. Aerospace engineering is not exempt from this modern trend, and the concepts developed in its courses follow the same path.

However, the attitude shown by students towards statistics is, generally, not very positive. This fact has been reported even from earlier stages such as secondary education [1]. Students show anxiety and a lack of confidence due to the mathematical component of statistics. As reported in several studies, the attitude shown towards a subject is a good predictor of the expected academic results [2].

The importance of attitude, experience, and previous success are essential to improve student performance in higher grades [3]. Student performance can then be improved through the design and development of positive activities. Project-based learning (PBL) has effectively demonstrated the ability to create positive activities and enhance learning [4]. Previous experiences have been carried out, in other subjects and courses related to Aerospace Engineering. For instance, the seminal work carried out at the Universidad Politécnica de Madrid (UPM) and the Technical University of Delft show effective learning and achievement through project-based learning [5], [6]. However, the homework planning process must be carried out carefully so that students are not discouraged, nor they achieve poor academic performance or learning [7].

The measurement of attitude is not simple and it requires indirect measures. Thus, survey-based methods have been developed to tackle this issue. For instance, some surveys have been proposed in this line such as the Statistics Attitude Survey (SAS,[8]), the Survey of Attitudes Toward Statistics Scale (SATS, [9]), and the fuzzy-set Qualitative Comparative Analysis (fsQCA, [1]). Similarly, Auzmendi [10] proposes the SAS survey, the most widely used assessment tool for students' attitudes in Spain.

In this article, we present how the attitude of aerospace engineering students at Universitat Politècnica de València (UPV) has improved in the statistics courses that we teach by introducing project-based 
learning. The article is structured as follows: Section 2 shows the methodology used for the analysis, the results of which are shown in Section 3. The conclusions reached are listed in Section 4.

\section{METHODOLOGY}

This section is divided into two subsections. The first one describes the methodology used to design the project-based activity, which has made it possible to improve the students' attitude towards statistics. In the second subsection, the methodology employed to assess students' appreciation is shown.

\subsection{Project-Based Activities}

The design of the project was carried out following a series of fundamental aspects for its realization. First of all, different areas of the Aerospace Engineering syllabus must be addressed. Second, the transversal competencies of the student must be promoted. Finally, an active role in the learning process should be given to students. For its design, the complementary aspect of the project aspect of this project was taken into consideration, as it allows students to put the knowledge acquired through lectures into action. In our project implementation, the project corresponded to $10 \%$ of the total marks of the course.

As a consequence of this, the design was carried out according to the following phases: establishment of objectives, timing, tasks and documentation, assessment of the student, and evaluation of the activity.

\subsubsection{Objectives:}

The objectives set in the subject are broken down into three large groups:

- Acquisition of the necessary knowledge of statistics included in the curriculum.

- Practice of statistical work procedures: data collection, analysis, reports, and inference.

- Development of transversal competencies of critical thinking, teamwork, problem-solving, and decision making, among others.

\subsubsection{Timing}

The project is structured in 5 sessions of two hours, as indicated in Figure 1. Each session takes place after the concepts have been developed in the lecture, and the procedures have been properly worked on in laboratory sessions. The project sessions end up with a report produced by the students, which provides for a series of questions posed in each task. The total time invested in the course is 18 weeks.

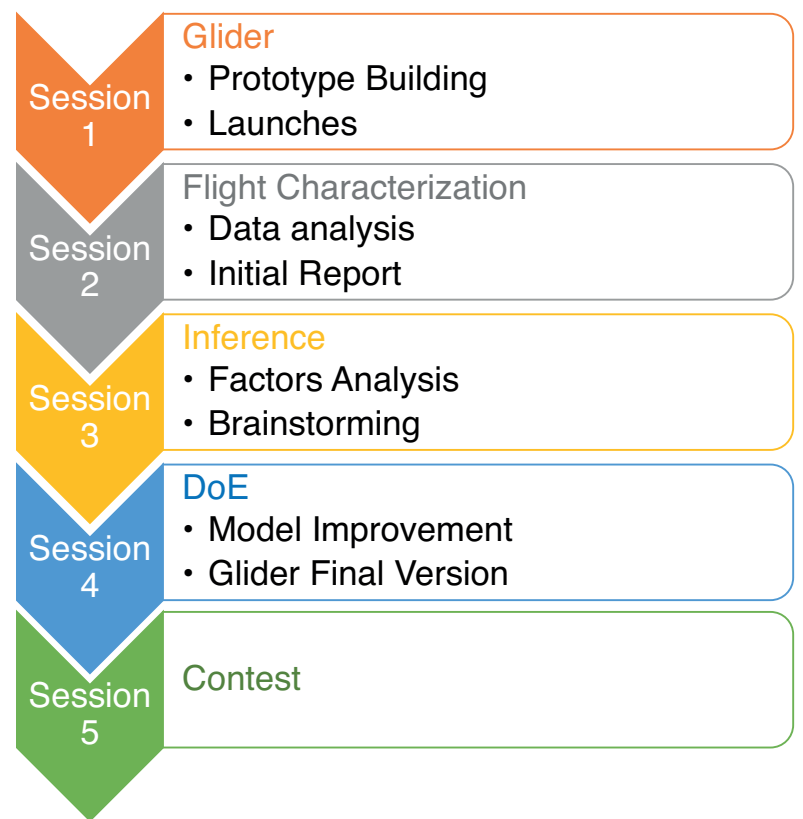

Figure 1. Structure of the project timing. 


\subsubsection{Tasks}

Figure 1 also shows the main objectives of each session and the procedures developed in each of the sessions. Assignments include procedures and instructions provided by lecturers, as well as templates to fill out with data related to the project work.

The first session pursues the objective of building a cardboard glider, taking measurements of the implemented prototype, and transferring these measurements to statistical software. Figure 2 shows some of the work carried out in the first session. Students work collaboratively as a team to build their gliders.
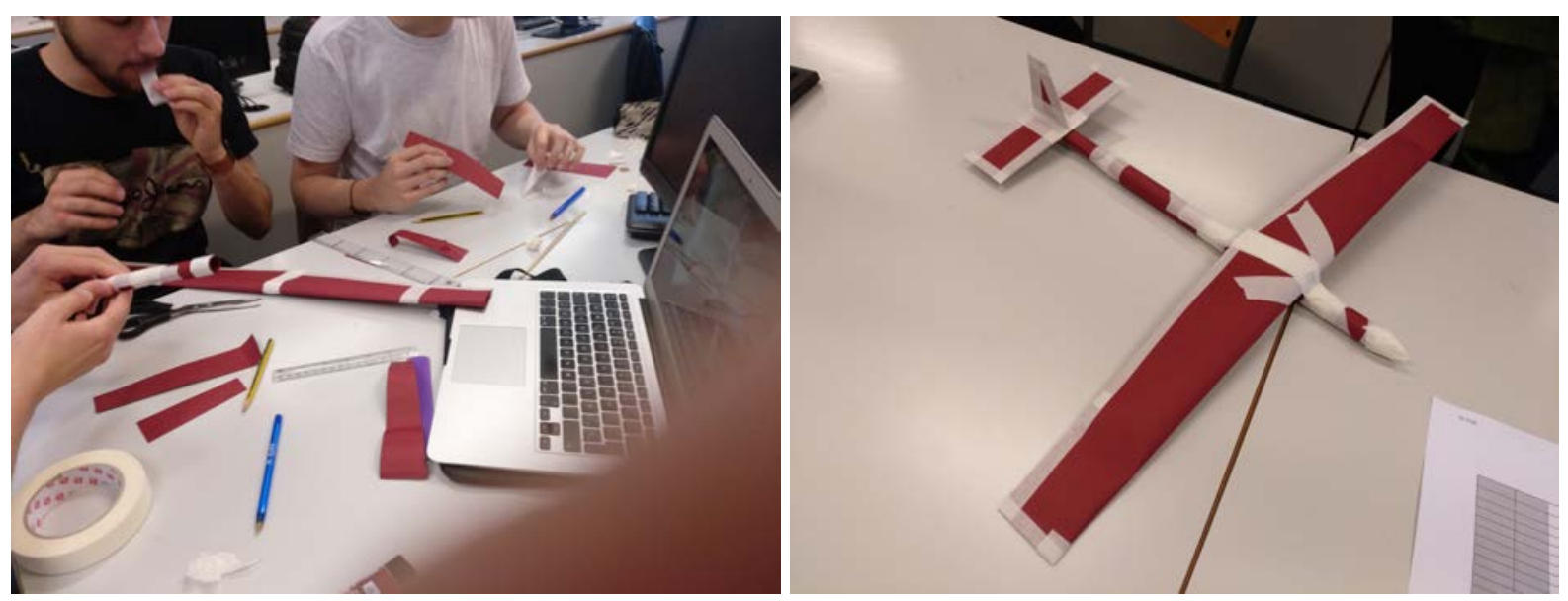

Figure 2. Session 1 pictures. Building the glider.

The second session focuses on descriptive statistics. Students must use the tools, metrics, and graphical procedures studied in the lectures to characterize the flight of the glider. The use of histograms, box and whisker graphs, frequency tables, and cross tabulation are some of the elements worked on in the session.

In the third session, the first aspects of inference are covered. Factor analysis, ANOVA and similar tools are employed. This session allows students to find relationships between aspects of the airplane design and its flight. This session ends up with a brainstorming activity to determine improvements that may be beneficial for the glider. Then, in the next session, a design of experiments can be carried out.

The fourth session comprises the design of experiments. Students execute the flight tests and analyze the results obtained. As a result of this session, students can make improvements to the original prototypes. Figure 3 shows some of the proposals made during the fourth session (Design of Experiments).
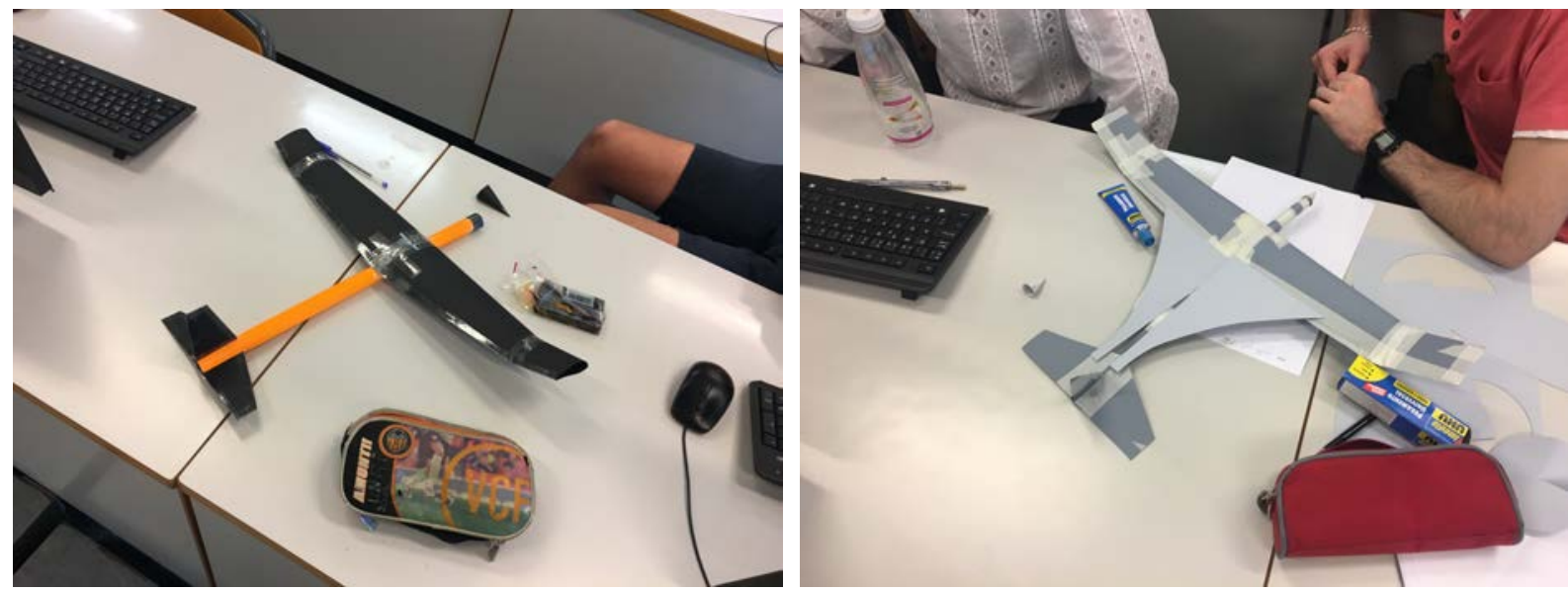

Figure 3. Session 4 pictures. Conducting the DoE.

The last session is arranged as a competition among teams. The teams have a chance to throw their prototypes several times to beat a baseline established by the teaching team. Prizes and bonuses are assigned based on the improvement obtained and the position achieved in the ranking of the competition. 


\subsubsection{Assessment}

The project activities are assessed as a part of the work carried out. Each task must be followed by a project submission, which is assessed by both lecturers and peers. This way, students assess each other and learn from their peers. The grades for each submission are, however, the sole responsibility of the teaching team. Lecturers evaluate the activity according to criteria established through a rubric system, and they rate the performance achieved by the teams.

\subsection{Evaluation of the activity}

A careful evaluation was carried out to determine the best choice among available methods to assess students' attitudes towards statistics. However, the current structure of the course does not allow the implementation of many of these assessment tools. For this reason, we decided to carry out a new and simple questionnaire where two fundamental dimensions of interest were assessed: Motivation and perceived academic result.

The first dimension seeks to analyze the student's perception of these types of activities, and the assessment of the activities and work carried out in the project. Three survey questions are proposed: Have you previously participated in your training stages in a project similar to this one? Do you think that the interest in this type of methodologies could be increased if more subjects were involved? and Have you found the proposed tasks interesting? Other open questions are included that help to receive feedback on the questions raised.

The second dimension is related to the student's perception of the achievement achieved in the subject, the acquisition of knowledge, and how it affects performance compared to the traditional teaching methodology. The questions proposed are: Does the teaching methodology seem effective to you? With the methodology used, have you detected positive changes compared to the traditional method (the one used in the first quarter)? and Has the project helped you understand the usefulness of statistics within your field of learning?

\section{RESULTS}

After conducting surveys among students during several consecutive academic years, the results can be observed in Figures 5 and 6 . The results observed in figure 5 are related to the motivational aspects. In it, it can be seen how $75 \%$ of the students had not participated in a project similar to this one in their degree. However, $71.3 \%$ of them opted for this methodology and that it should be exported to other subjects. Finally, the tasks proposed during the activity were to the liking of the students, being interesting and motivating.

\section{HAVE YOU PREVIOUSLY PARTICIPATED IN YOUR TRAINING STAGES IN A PROJECT SIMILAR TO THIS ONE?}

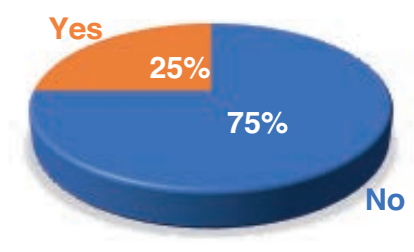

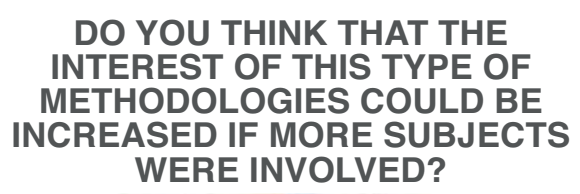
WERE INVOLVED?

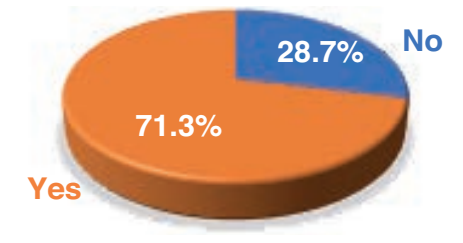

\section{DID YOU FIND THE PROPOSED \\ TASKS INTERESTING?}

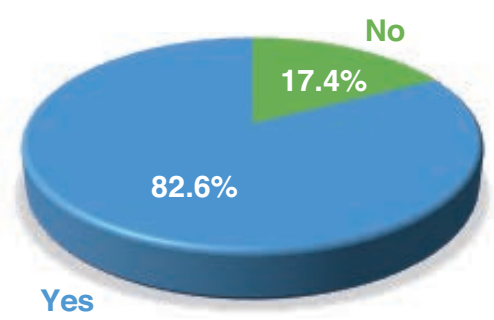

Figure 5. Results of the test. Study area: Motivation. 
This shows a change in the students' attitude towards statistics since motivation increased in all of them. The students felt involved in the course of the activities, and they imbued that motivation to the performance of the project activities.
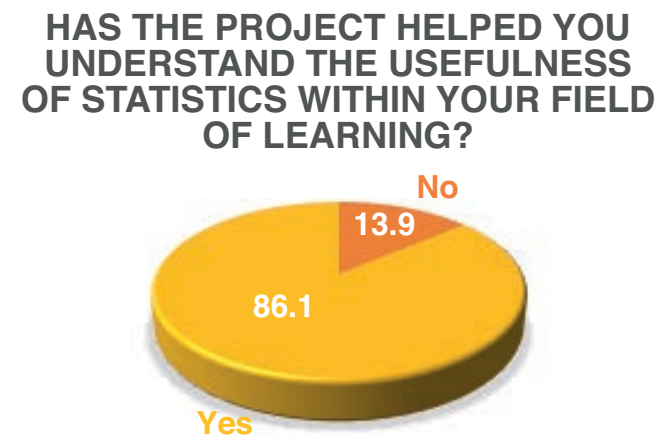

\section{IS THIS TEACHING METHOD EFFECTIVE?}

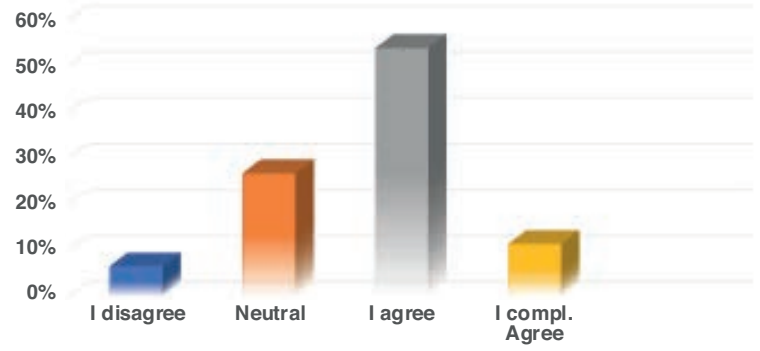

\section{HAVE YOU DETECTED POSITIVE CHANGES COMPARED TO TRADITIONAL METHODS}

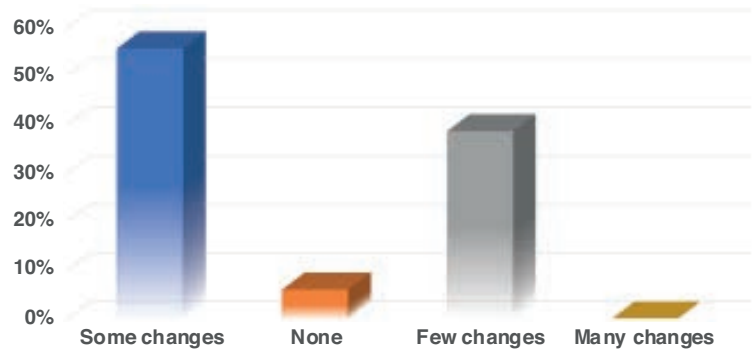

Figure 6. Results of the test. Study area: Perceived academic result.

On the other hand, a fundamental part of the development of project-based learning is the achievement of the learning objectives. The average marks of the years included in this analysis were not only higher than those of previous years, but also the evaluation of transversal competencies improved significantly. Figure 6 shows the student's perception of this methodology and learning. Most of the students $(86.1 \%)$ suggest that carrying out these activities helped to better understand the statistical concepts worked on. The vast majority of students agree that the methodology was effective, and in general positive changes were detected compared to the traditional methodology.

\section{CONCLUSIONS}

This article has presented the study carried out in the course of statistics in BSc. Aerospace Engineering at Universitat Politècnica de València in the last few year. In this article, we analyze the variation of the students' attitude towards statistics when introducing project-based learning. Firstly, we introduced the project design and the work carried out in each of the project sessions. Secondly, the evaluation of the improvement achieved through project-based learning is presented.

The survey results show a substantial improvement in the students' assessment of the positive motivation experienced through the realization of the project. In addition to this, it has been proved that the academic results also significantly increase. The student's perception of their learning is positive and, in general, a positive assessment of project-based methodology is observed.

In short, the use of project-based learning reinforces the knowledge acquired and it increases the motivation of the students, especially when faced with complex subjects such as statistics.

\section{ACKNOWLEDGEMENTS}

The authors would like to thank the UPV and their support by funding this article with Education Improvement and Innovation Project (PIME-185). 


\section{REFERENCES}

[1] Á. Peiró-Signes, Ó. Trull, M. Segarra-Oña, and J. C. García-Díaz, "Attitudes towards statistics in secondary education: Findings from fsQCA," Mathematics, vol. 8, no. 5, pp. 1-17, 2020, doi: 10.3390/MATH8050804

[2] B. Biens, "Teaching the Relevance of Statistics Through Consumer-Oriented Research," Teach. Psychol., vol. 12, no. 3, pp. 168-169, Oct. 1985, doi: 10.1207/s15328023top1203_16

[3] C. Ramirez, C. Schau, and E. Emmioğlu, "The importance of attitudes in statistics education," Stat. Educ. Res. J., vol. 11, no. 2, pp. 57-71, 2012.

[4] T. Y. E. Siswono, S. Hartono, and A. W. Kohar, "Effectiveness of project based learning in statistics for lower secondary schools," Eurasian J. Educ. Res., vol. 18, no. 75, pp. 197-212, 2018, doi: 10.14689/ejer.2018.75.11

[5] S. Pindado, J. Cubas, E. Roibás-Millán, and F. Sorribes-Palmer, "Project-based learning applied to spacecraft power systems: a long-term engineering and educational program at UPM University," CEAS Sp. J., vol. 10, no. 3, pp. 307-323, 2018, doi: 10.1007/s12567-018-0200-1

[6] G. N. Saunders-Smits, P. Roling, V. Brügemann, N. Timmer, and J. Melkert, "Using the engineering design cycle to develop integrated project based learning in aerospace engineering," EE 2012 - Int. Conf. Innov. Pract. Res. Eng. Educ. Conf. Proc., no. September, 2012.

[7] S. Han, R. Capraro, and M. M. Capraro, "How Science, Technology, Engineering, and Mathematics (Stem) Project-Based Learning (Pbl) Affects High, Middle, and Low Achievers Differently: the Impact of Student Factors on Achievement," Int. J. Sci. Math. Educ., vol. 13, no. 5, pp. 1089-1113, 2015, doi: 10.1007/s10763-014-9526-0

[8] D. M. Roberts and E. W. Bilderback, "Reliability and Validity of a Statistics Attitude Survey," Educ. Psychol. Meas., vol. 40, no. 1, pp. 235-238, Apr. 1980, doi: 10.1177/001316448004000138

[9] C. Schau, J. Stevens, T. L. Dauphinee, and A. Del Vecchio, "The development and validation of the survey of attitudes toward statistics," Educ. Psychol. Meas., vol. 55, no. 5, pp. 868-875, 1995.

[10] E. Auzmendi Escribano, Las actitudes hacia la matemática-estadística en las enseñanzas media y universitaria [Attitudes towards statistical mathematics in secondary and university education]. Bilbao, Spain: Mensajero, D.L., 1992. 